\title{
We remember with gratitude their great contributions in laying the foundations of Plastic Surgery in this Country.
}

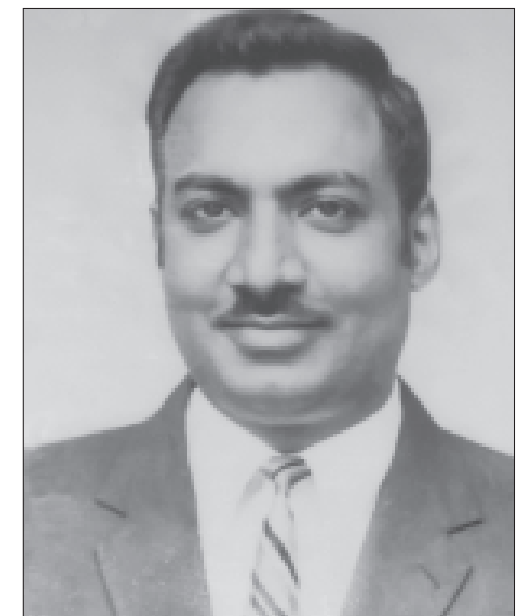

Late Dr. Pervez Bazleil

Dr. Pervez Bazleil was born in Ludhiana, India. He was a renowned plastic surgeon. Dr. R. J. Garst brought this great man to this country in 1974 to treat the crippled freedom fighters of our great liberation war. This is the beginning of the history of plastic surgery in Bangladesh. He died in the year of 1977.

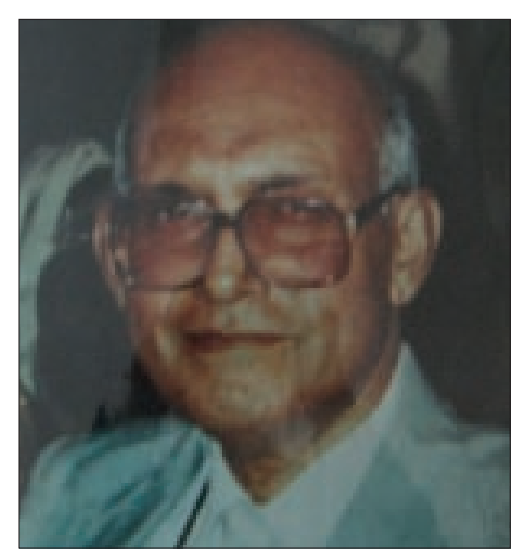

Late Dr. Mohammed Shahidullah

Professor Dr. Mohammed Shahidullah was born in Kushtia, Bangladesh, on March 18, 1934. He graduated from Dhaka Medical College in 1958. He obtained his FRCS from Edinburgh in 1971 and spent the next 10 years in various hospitals in UK. In 1981, Dr. Shahidullah returned to Bangladesh to join DMCH and retired as Professor of Plastic Surgery in 1995. After retirement, he joined BIRDEM hospital. He was the founder President of Plastic and Reconstructive Surgeons Association (PARSA) and the founder Chairman of the Society of Rehabilitation of Burn Victims (SRBV). He passed away at the age of 66 on July 8, 2000.

\section{Society News}

This is for the information of all that the 1st National Conference on Plastic Surgery 'Plasticon 2010' is going to be held on 11th May 2010. Preparation for the conference is underway and a comprehensive one day scientific programme has been chalked out in this regard. The scientific sessions will encompass the scopes of plastic surgery in Bangladesh as much as possible, with special emphasis on topics like trauma and plastic surgery, pressure sores, cleft lip and palate, hand surgery, burn care, keloids and hypertrophic scars, breast reconstruction, cancer reconstruction, hair transplant and aesthetic surgery.

Registration for the conference is open to all and is a prerequisite for attending the event. Further details of the conference are available at the Department of Plastic Surgery, Room no. 98, Dhaka Medical College \& Hospital, Dhaka-1000, Bangladesh. E-mail: banglaplast@gmail.com. 